\title{
Supplement information
}

\section{Enhanced Charge Efficiency and Electrode Separation Utilizing Magnetic Carbon in Flow Electrode Capacitive Deionization}

Junjun Ma, ${ }^{1}$ Tie Gao, ${ }^{1}$ Yunfei He, ${ }^{1}$ Kuichang Zuo, ${ }^{2,3 *}$ Qilin Li,,${ }^{2,3}$ Peng Liang ${ }^{1 *}$

${ }^{1}$ State Key Joint Laboratory of Environment Simulation and Pollution Control, School of Environment, Tsinghua University, Beijing 100084, PR China

${ }^{2}$ Department of Civil and Environmental Engineering, Rice University, MS 319, 6100 Main Street, Houston 77005, USA

${ }^{3}$ NSF Nanosystems Engineering Research Center Nanotechnology-Enabled Water Treatment, Rice University, MS 6398, 6100 Main Street, Houston 77005, USA

*Corresponding author:

Kuichang Zuo: kuichang.zuo@rice.edu (Email), (+1)8322307547 (Tel)

Peng Liang: liangpeng@tsinghua.edu.cn (Email),+86 1062796790 (Tel) 


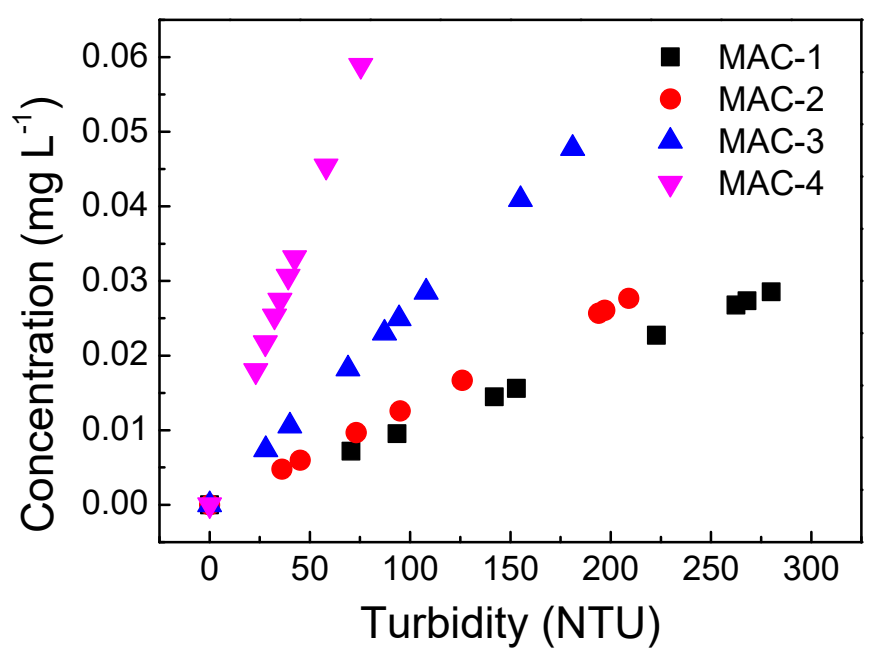

Figure S1. Linear relationship between electrode concentration and turbidity.

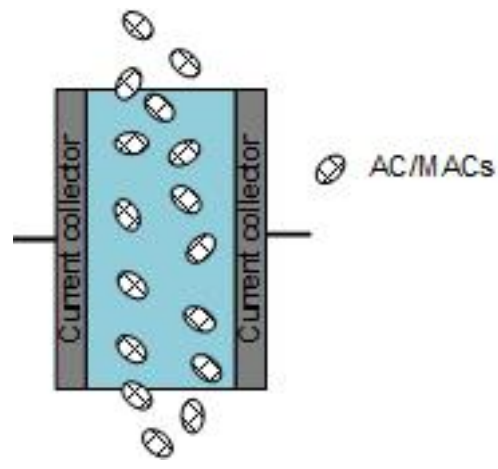

Figure S2. One-chamber cell used for electrochemical characterization.

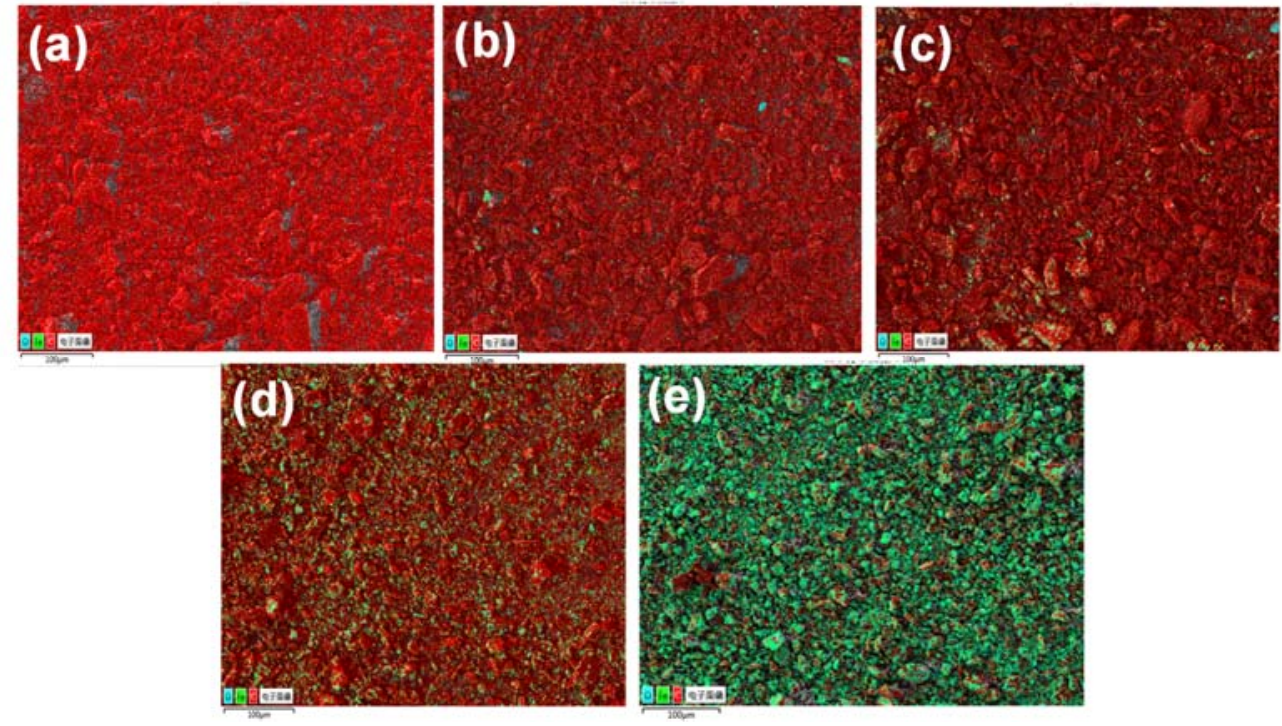

Figure S3. EDS images of AC and magnetic carbon composites. (a) AC; (b) MAC-1; 
(c) MAC-2; (d) MAC-3; (e) MAC-4.
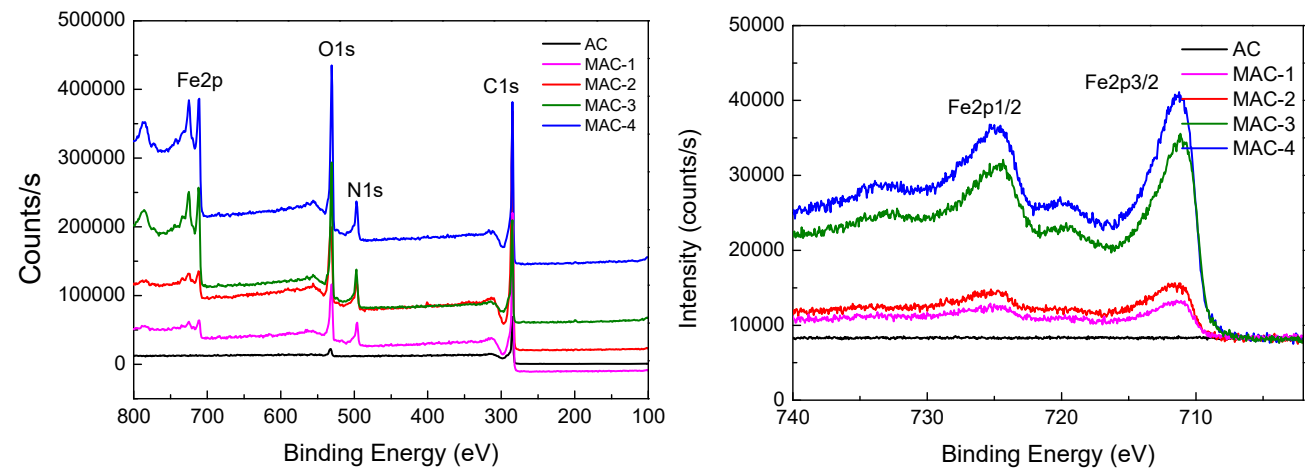

Figure S4. XPS spectra of AC and MACs. (left) Full spectrum scan; (right) Fe 2p.
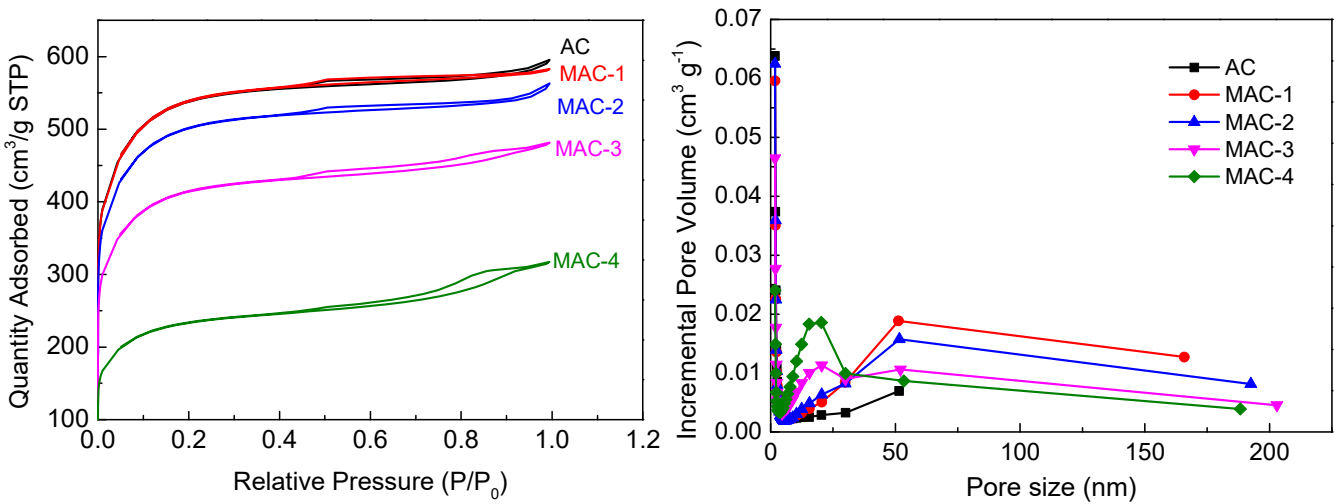

Figure S5. $\mathrm{N}_{2}$ adsorption-desorption isotherm (left) and pore distribution (right) of $\mathrm{AC}$ and MACs measured at $76 \mathrm{~K}$.

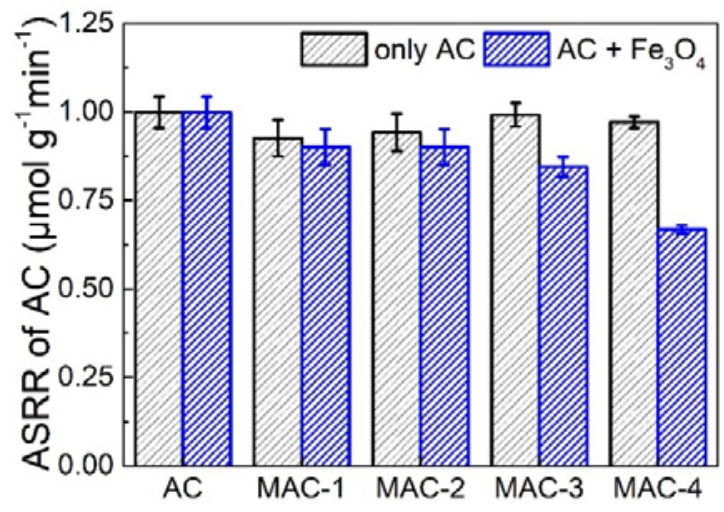

Figure S6. Average salt removal rate (ASRR) of AC and MAC electrodes when normalized by the mass of total electrode (including both $\mathrm{AC}$ and $\mathrm{Fe}_{3} \mathrm{O}_{4}$ ) or only by the mass of $\mathrm{AC}$ content (excluding the mass of $\mathrm{Fe}_{3} \mathrm{O}_{4}$ ). 


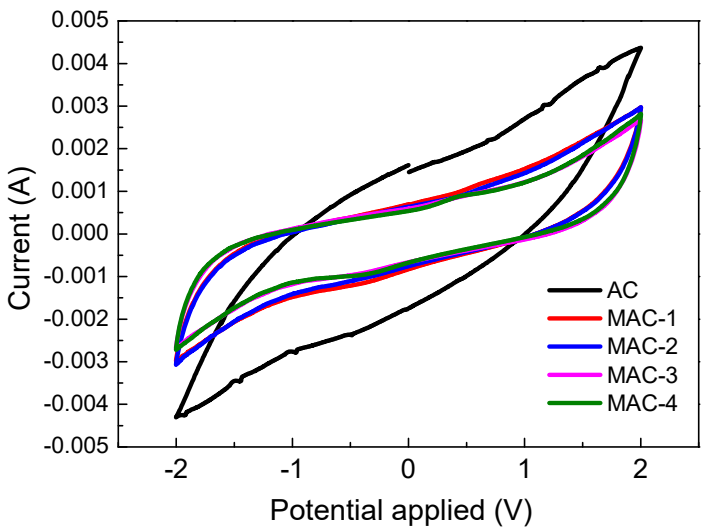

Figure S7. CV curves of the AC and MACs at a potential scanning rate of $5 \mathrm{mVs}^{-1}$.

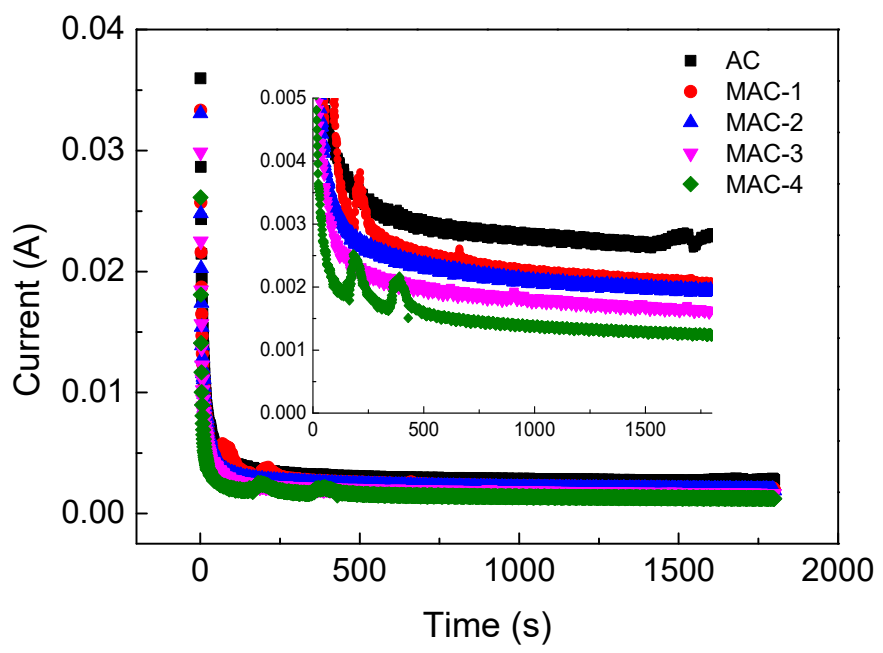

Figure S8. Desalination currents of AC and MAC electrodes.
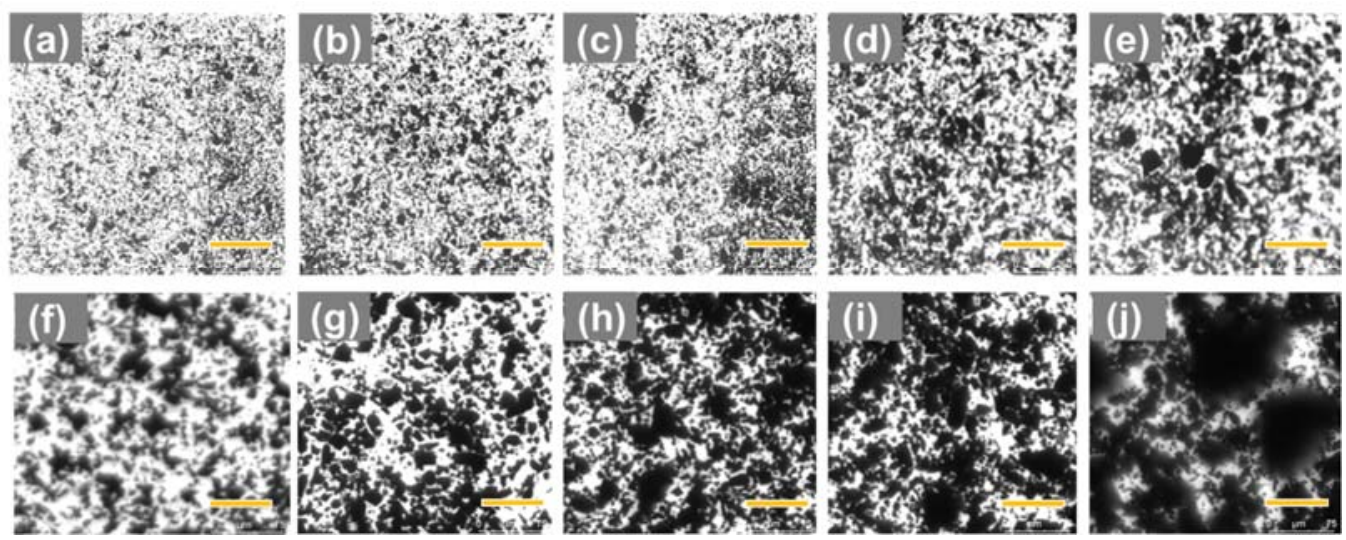

Figure S9. Aggregation of $\mathrm{AC}$ and $\mathrm{MAC}$ suspension $(0.1 \mathrm{wt} \%)$ under optical microscope. (a, f) AC; (b, g) MAC-1; (c, h) MAC-2; (d, i) MAC-3; (e, j) MAC-4. The 
scale bar in a-e and $\mathrm{f}-\mathrm{j}$ are 200 and $75 \mu \mathrm{m}$, respectively.

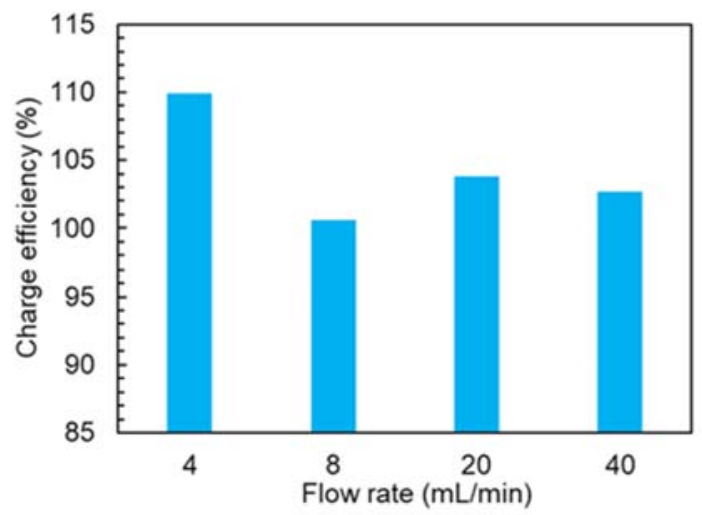

Figure S10. Charge efficiency of MAC-2 electrode at various flow rates.

Calculation of ion migration speed and interparticle distance in $\mathrm{AC}$ and MAC systems

\section{Ions migration velocity}

(1) Ions migration with hydraulic flow, of

Since the flow rate of suspended electrodes was $4 \mathrm{~mL} / \mathrm{min}$, and the sectional size of the flow channel was $2 \mathrm{~mm} \times 2 \mathrm{~mm}$, the $\mathrm{v}_{f}$ can be calculated as below:

$$
u_{f}=\frac{4 \mathrm{~mL} / \mathrm{min}}{2 \mathrm{~mm} \times 2 \mathrm{~mm}}=\frac{4 \mathrm{~cm}^{3} / \mathrm{min}}{0.04 \mathrm{~cm}^{2}}=100 \mathrm{~cm} / \min =1.667 \times 10^{-2} \mathrm{~m} / \mathrm{s}
$$

(2) Ions migration velocity under electrical field, $\gamma_{\mathrm{Na}^{+}}$, can be calculated using the equation below:

$\gamma_{\mathrm{Na}^{+}}=U_{+}\left(\frac{d E}{d L}\right)$

Where $U_{+}$is ion mobility, $\mathrm{E}$ is the applied voltage $(1.2 \mathrm{~V})$; $\mathrm{L}$ is the distance between two current collectors $(4.5 \mathrm{~mm})$.

$U_{+}=5.19 \times 10^{-8} \mathrm{~m}^{2} /(\mathrm{s} \mathrm{v})$

$\gamma_{\mathrm{Na}^{+}}=U_{+}\left(\frac{d E}{d L}\right)=5.19 \times 10^{-8} \times \frac{1.2}{0.0045}=1.384 \times 10^{-5} \mathrm{~m} / \mathrm{s}$

2. Distance between uniformly suspended AC particles and MAC aggregates 
in $2.5 \%$ slurry electrode

(1) Distance between uniformly suspended AC particles

According to Figure 1a, the size of $\mathrm{AC}$ and MAC particles ranged from 1 to $10 \mu \mathrm{m}$. To simplify calculation, here we assume that all the AC and MAC particles are ideal balls with a diameter of $5 \mu \mathrm{m}$. The density of activated carbon is $\rho=2 \mathrm{~g} / \mathrm{cm}^{3}$, therefore, the mass of each $\mathrm{AC}$ ball $\left(\mathrm{m}_{\mathrm{AC}}\right)$ is

$$
m_{\mathrm{AC}}=\rho \times \mathrm{V}=\rho \times \frac{4}{3} \pi(2.5 \mu \mathrm{m})^{3}=1.31 \times 10^{-10} \mathrm{~g}
$$

Therefore, the total number of $\mathrm{AC}$ particles $\left(N_{\mathrm{AC}-1}\right)$ in $1 \mathrm{~mL} 2.5 \%$ slurry can be calculated as below:

$$
N_{A C}=\frac{1 g \times 2.5 \%}{1.31 \times 10^{-10}}=1.91 \times 10^{8}
$$

If uniformly suspending these $\mathrm{AC}$ particles in $1 \mathrm{~mL}$, then the interparticle distance can be calculated as below:

$$
D_{A C}=\frac{1 \mathrm{~cm}}{\sqrt[3]{1.91 \times 10^{8}}}=17.4 \mu \mathrm{m}
$$

(2) Distance between uniformly suspended MAC aggregates

In MAC-4, the mass ratio of $\mathrm{AC}$ is $68.8 \%$, therefore the total number of MAC particles in $1 \mathrm{~mL}$ of electrolyte is:

$$
N_{\text {MAC-4 }}=\frac{1 \mathrm{~mL} \times 2.5 \% \times 68.8 \%}{1.31 \times 10^{-10} \mathrm{~g}}=1.31 \times 10^{8}
$$

As shown in Figure S7j, the size of MAC-4 aggregates in $0.1 \mathrm{wt} \%$ of solution can reach $\sim 100 \mu \mathrm{m}$. Therefore, the aggregates can be even bigger in $2.5 \mathrm{wt} \%$ of suspended electrodes. To simplify calculation in this assessment, here we assume that all the MAC4 aggregates having a diameter of $100 \mu \mathrm{m}$ in $2.5 \mathrm{wt} \%$ of suspended electrodes. Therefore, we can calculate the number of MAC-4 particles in each MAC-4 aggregate ( $N_{\text {MAC-4 }}$ in one aggregate), the total number of MAC-4 aggregates (NMAC-4 aggregates), and the average between each MAC-4 aggregate ( $\left.D_{\text {aggregate }}\right)$.

$$
\begin{aligned}
& N_{\text {MAC-4inoneaggregate }}=\frac{4 \pi}{3} \times\left(\frac{100}{2 \times 5}\right)^{3}=4188 \\
& N_{\text {MAC-4aggregate }}=\frac{1.31 \times 10^{8}}{4188}=3.13 \times 10^{4}
\end{aligned}
$$




$$
D_{\text {aggregate }}=\frac{1 \mathrm{~cm}}{\sqrt[3]{3.13 \times 10^{4}}}=316.96 \mu \mathrm{m}
$$

Table S1. Fe and carbon amount when preparing the MAC samples

\begin{tabular}{cccc}
\hline & $\begin{array}{c}\mathrm{AC} \\
(\mathrm{g})\end{array}$ & $\begin{array}{c}\mathrm{FeCl}_{3} \cdot 6 \mathrm{H}_{2} \mathrm{O} \\
(\mathrm{g})\end{array}$ & $\begin{array}{c}\mathrm{FeCl}_{2} \cdot 4 \mathrm{H}_{2} \mathrm{O} \\
(\mathrm{g})\end{array}$ \\
\hline AC & 50 & 0 & 0 \\
MAC-1 & 50 & 4.63 & 1.70 \\
MAC-2 & 50 & 7.28 & 2.68 \\
MAC-3 & 50 & 24.50 & 9.01 \\
MAC-4 & 50 & 51.64 & 18.99
\end{tabular}

Table S2. Specific surface area and pore analysis of AC and MACs

\begin{tabular}{cccccc}
\hline Material & AC & MAC-1 & MAC-2 & MAC-3 & MAC-4 \\
\hline Specific surface area $\left(\mathrm{m}^{2} \mathrm{~g}^{-1}\right)$ & 2008 & 1974 & 1870 & 1544 & 860 \\
Average pore size $(\mathrm{nm})$ & 2.37 & 2.73 & 2.85 & 3.11 & 4.23 \\
\hline
\end{tabular}

Table S3. Capacitance and resistance of AC and MACs obtained from EIS and CV results.

\begin{tabular}{cccccc}
\hline Material & AC & MAC-1 & MAC-2 & MAC-3 & MAC-4 \\
\hline Specific capacity $\left(\mathrm{F} \mathrm{g}^{-1}\right)$ & 21.65 & 19.46 & 18.69 & 17.59 & 17.50 \\
Ohmic resistance $(\Omega)$ & 74.8 & 50.3 & 43.2 & 41.4 & 29.4 \\
\hline
\end{tabular}

